\title{
The Project BIBLIO - Boosting Digital Skills and Competencies for Librarians in Europe: An Innovative Training Model for Creating Digital Librarian
}

\section{Nicola Barbuti, Sara Di Giorgio \& Altheo Valentini}

To cite this article: Nicola Barbuti, Sara Di Giorgio \& Altheo Valentini (2019) The Project BIBLIO - Boosting Digital Skills and Competencies for Librarians in Europe: An Innovative Training Model for Creating Digital Librarian, International Information \& Library Review, 51:4, 300-304, DOI: 10.1080/10572317.2019.1669935

To link to this article: https://doi.org/10.1080/10572317.2019.1669935

\section{Nov 2019.}

Submit your article to this journal $\pi$

\section{山 Article views: 39}

Q View related articles $\sqsubset$

View Crossmark data $₫$ 
Anna Maria Tammaro, Column Editor, DILL International Master Digital Library Learning, University of Parma, Parma, Italy

\title{
COLUMN EDITOR'S NOTES
}

The "Digital Heritage: Spotlight on Europe" column examines technological advances internal and external to cultural institutions. The digital shift changed radically how cultural heritage is made, disseminated, distributed, accessed, consumed, and monetized. One of the most important revolutions is that the user role changed dramatically, shifting from passive observers to active participants and content producers with many new and exciting opportunities for engagement, creative use, and access. The strength of the column is its broad, international focus, and contributors are encouraged to explore issues and recent advances in digital heritage theories, methodologies, standards relevant to the European region, as well as the larger, global audience. Interested authors are invited to submit proposals and articles to the column editor at annamaria.tammaro@unipr.it. Please include "ILLR submission" in the subject line of the e-mail.

\section{The Project BIBLIO - Boosting Digital Skills and Competencies for Librarians in Europe: An Innovative Training Model for Creating Digital Librarian}

\author{
Nicola Barbuti ${ }^{\mathrm{a}} \mathbb{D}$, Sara Di Giorgio ${ }^{\mathrm{b}}$ and Altheo Valentini ${ }^{\mathrm{c}}$ \\ a Università Degli Studi di Bari Aldo Moro, Bari, Italy; ${ }^{b}$ Istituto Centrale per il Catalogo Unico, Rome, Italy; ${ }^{\mathrm{C} E G I n A}$ S.r.I, Foligno, Italy
}

\begin{abstract}
The role of digital libraries is changing, offering new services supporting the user's activities. Libraries and librarians are facing the need of a reinvention of models, ways of working and techniques. The project BIBLIO - Boosting digital skills and competencies for librarians in Europe: A new perspective for curation of Digital Cultural Heritage addresses the skills gap in the library sector due to the digital transformation that is changing the role of libraries and library professionals. The paper describes how the project is planning to facilitate the acquisition of digital and transversal competencies for library professionals, by setting up a system for competencies assessment, learning offer and validation and recognition.
\end{abstract}

\section{KEYWORDS}

Digital librarians; digital cultural heritage; digita libraries; Library and Information Science (LIS) education and training

\section{Introduction}

In the rapidly changing digital world, the amount of digitized content is constantly growing. "Digital Transformation" is changing the perspective to access and evaluate knowledge (Lau, Tammaro, \& Bothma, 2012). Digitization of libraries, archives, museums, monuments created an enormous amount of data which floats online as a digital magma. People use this materialization of Borges "Library of Babel" in a one-to-one approach without intermediate figures who can direct their information needs. This new way to use data shared online foster a democratization of culture and knowledge whose effects are not always positive. Users scroll through digital data without knowing direction to go on, and a lot of them assume fake information as source of knowledge.
In this scenario, the role of libraries is changing: libraries and digital libraries must play a primary role to foster a correct approach to knowledge by creating an effective digital culture for their users, offering them new services to support their fruition of analogical and digital content.

So, libraries and mostly librarians are facing the need of a reinvention of their models, ways of working and techniques. The risk of a digital competencies gap is high. Library staff, researchers, and users need more training in order to be able to cope with new and different topics: digital resource management, sharing, enhancement and preservation, data access, blockchain, text and data mining, etc.

The theoretical discussion about the innovation in education and training of librarians to face the 
digital transformation started several years ago (Colombati \& Giusti, 2016; Del Rosso \& Lampert, 2013; Pomerantz et al., 2009; Sreenivasulu, 2000; Tammaro, 2016; Tammaro \& Myburg, 2012, 2013; Tammaro, Verheul, \& Witt, 2011).

Some fundamental studies and researches provides innovative perspectives on the discipline and profession of Library and Information Science (LIS) and on librarians education, focusing on the skills and competencies the students' needs to become digital curators and librarians who can engage with present and future digital information (Beagrie, 2008; Tammaro, Casarosa, \& Madrid, 2013; Walek, 2018).

These works examine competences for practice as well as some of the international changes in the nature of higher education, some of them suggesting models that could be used internationally to educate librarians for their new roles and social responsibilities in a digitized, networked world.

What arises from the discussion about the definition of digital librarian and/or digital curator is that digital libraries and digital cultural heritage are far away from physical libraries and from tangible and intangible cultural heritage. The management of new digital resources and services for users addresses all the different kind of digital cultural collections which today float in the Web. We cannot associate digital libraries with libraries as we know them: a digital collection encloses not only digitized books, but also resources of totally different kind and object, whose management, fruition and preservation need specific digital skills and competences and no more only LIS competences.

Managing digital resources and collections and offering digital services for users are another work that needs digital librarians, that is digitally skilled professionals provided with solid human knowledge and competences together with deep competences on digitization of cultural heritage and management of digital cultural heritage and digital services. This last competences lack quite totally, though it has become an emergency. So, today the time to test some practical experiments comes on.

The project BIBLIO - Boosting digital skills and competencies for librarians in Europe ${ }^{1}$ we describe in this paper is a first attempt to create European curricula for filling the digital skills and competences gap today existing between digital transformation and LIS, librarians and curators of cultural heritage, aiming at creating the innovative professional profile of digital librarian.

\section{The BIBLIO project}

The BIBLIO project ${ }^{2}$ was promoted by the Scientific Committee composed by Department of Humanities DISUM of University of Bari Aldo Moro (UNIBA), on behalf of Italian Network for Education on Digital Cultural Heritage, Arts and Humanities (DiCultHer), and by Istituto Centrale per il Catalogo Unico (ICCU) of MiBACT. This Erasmus + Program aims at tackling skills gaps with regard to one or more occupational profiles by identifying specific existing or emerging sectors of labor market needs, and by enhancing the responsiveness of initial and continuing vocational education and training (VET) systems, at all levels, to the labor market needs. In particular, Lot 2: Sector Skills Alliances for design and delivery of VET will work to design and deliver common training content for vocational programs for one or several related professions in a sector, as well as teaching and training methodologies for European professional core profiles. A particular focus is to be put on work-based learning, providing learners with the skills required by the labor market.

The project faces the Erasmus Program aiming to create an innovative model for education and training of new LIS professionals who will be trained to create, manage, care for, enhance and preserve digital libraries and to offer users advanced digital services. This is a first-rate educational and training challenge as there are still few university courses in Italy and Europe that deal with the domain of digital applied to LIS.

BIBLIO aims at developing skills and competences in the library sector and at creating the innovative profile of digital librarian by introducing the concept of digital transformation, through the sustainable cooperation between key stakeholders in the sector, public authorities and VET providers, and supporting the development of 
VET curricula of Library operator (EQF 3) and of "Library expert" (EQF 6). In fact, we think that providing librarians with up-to-date digital skills can also provide invaluable support to library users, and will personally benefit from better career prospects.

The project aligns with other initiatives involving some Consortium partners. The Department DISUM of UNIBA together with EGINA Ltd are currently working on Erasmus + project Safeguarding Intangible and Cultural Values and Heritage - SILVHER, which develops a new design for training course related to management and digital creativity for Cultural Heritage.

DISUM is also involved in two national projects, Biblioteca di Comunità UNIBA and Biblioteche Scolastiche. The two projects involve the digitization of the libraries of UNIBA and of Liceo "G. De Sanctis" of Trani, a city in the province of Bari, aimed at creating a single innovative digital ecosystem that will provide users with advanced digital labs and services. The projects will also include training activities for librarians of the two institutions that will be involved in ecosystem management and in creating and offering users innovative digital services.

ICCU is involved in several international projects. Among them, the Institute is lead partner of inDICEs - Measuring the Impact of Digital Culture project funded by the European Commission within Horizon 2020. ICCU will coordinate a consortium formed by 14 scientific partners from nine Europeans countries. The project aims to provide policymakers and managers in the cultural heritage and creative industries sector with useful tools and strategies to fully understand the social and economic impact of digitizing cultural heritage as well as to support the innovative re-use of cultural heritage.

\section{Methodology}

The project BIBLIO addresses the skills gap in the library sector due to the digital transformation by facilitating the acquisition of digital and transversal skills for library and cultural heritage professionals, setting up a system for skill assessment, learning offer and validation and recognition.
The project will support the development of two VET curricula, one for Library operator (EQF 3) and the other for Library expert (EQF 6). Skills and competences developed will be mapped within the EntreCOMP and DigCOMP frameworks and a strong work-based learning component will be the main feature of the project.

An important feature of the project actions will be the promotion of the transnational mobility of learners, in order to make them mobile and flexible to adapt to the evolving international labor market.

\section{Educational and training activities}

The project will start by analyzing and comparing the training needs and the existent offer in the LIS and in some other cultural heritage sectors related to digital libraries, in order to identify a set of emerging new job role profiles.

For each one of them, a modular VET curriculum addressing relevant EQF level will be designed, applying a specific VET methodology based on learning outcomes and on the blended learning principles, in order to facilitate the acquisition of knowledge, competences, and skills based on the exploitation of various learning settings.

The delivery of the VET curricula will base on a set of digital Open Educational Resources (OERs) that will be developed to support the acquisition of more than 40 digital and transversal competences.

Based on the training contents previously identified, project partners will develop:

1. a MOOC addressed to library professionals for acquiring the identified competencies of new job role profiles;

2. a Specialization Training Course including faceto-face, virtual learning, project-based learning, and a work-based learning (WBL) phases. Training will be delivered via an online platform that stimulates sharing and exchange of knowledge, experiences, and best practices. WBL phase will be based on the principle of inter-generational learning. 
European instruments ${ }^{3}$ (EQF, ECVET, and EQAVET) will be applied, facilitating the recognition and validation of qualifications. Job role profiles will be mapped to $\mathrm{ESCO}^{4}$ and e-CF. ${ }^{5}$

\section{Objectives and expected outcomes}

BIBLIO project addresses a first-level challenge in the LIS sector. Contemporary libraries manage many different typology of materials, no more only books and serials as it was up to 30 years ago.

Digital resources and related digital services are the last in time, and perhaps they are the most complex artifact to manage. In fact, many digital libraries enclose not only digital resources reproducing books or other types of documents, they increasingly manage also several digital entities created with different technologies and methodologies: 3D creation, Augmented Reality, visual art, etc.

Contemporary librarians need to organize and to manage all of this digital magma for fruition of users, and to organize new efficient services for enabling them to access to, and to interact with digital collections. As an example, Digital Literacy should be one first-rate service that librarians should provide users of their libraries, but there is not structured digital education in libraries either for librarian or for users.

The project aims to fill this gap structuring a teaching model that will provide librarians with needed digital skills to face their new role, enabling them to create, manage, offer users digital libraries and related advanced digital services.

Specific objectives of the project are:

- to identify the existing and emerging skills needs for the library sector, also feeding this intelligence into the European Skills Panorama;

- to support the development of highly skilled, qualified and mobile workforce in the sector, adapting them to the labor market needs;

- to promote work-based learning in VET, also supported by a relevant mobility content;

- to support the development of relevant VET qualifications and their recognition at EU level.

BIBLIO project will have a significant impact mostly on library professionals, unemployed people in libraries sector, but also on people engaged in other broader fields of digital innovation applied to cultural heritage by enabling them both to manage the new digital cultural heritage and to offer innovative services for users.

The project will promote the acquisition of digital skills for librarians by its innovative training methodology, which will facilitate the intergenerational learning among young trainees and expert professionals, as through an action plan, trainees will bring new ideas and techniques to the hosting organization, promoting their digitalization. The acquired digital skills and competences will be mapped comparing them with the DigComp framework. ${ }^{6}$

The design of curriculum and the teaching activities will address the following EUROSTAT RAMON statistical classification of the economic sector $^{7}$ related to cultural heritage: Arts, Entertainment and Recreation: 91.1 Libraries, archives, museums, and other cultural activities.

\section{Conclusions}

The BIBLIO project is the output of twenty years of research, study and reflection by the UNIBA and ICCU partners focused on the impact of the digital transformation on cultural heritage and the challenges it has generated in LIS sector.

The digital revolution brought many complex and different challenges, and among them, the renewal of libraries and librarians role in the new scenarios of knowledge and information created by digital and digitization is one of the most important.

The creation of training models aiming to provide libraries and cultural heritage professionals with digital skills and knowledge is a firstrate need.

The main goal of the project is to fill this training gap today existent by this need and the state-of-the-art of LIS of librarian education, planning targeted courses for creating the new professional profile of digital librarian.

This is a first attempt to design and realize an international course to create an European new professional profile in the LIS sector. The challenge is important, now we are starting to address it. 


\section{Notes}

1. Funding Agency: European Commission - Call EACA03-2018, Erasmus + Program - Sector Skills Alliances in Vocational Education and Training.

2. The Project coordinator is the Department of Humanities (DISUM) of University of Bari Aldo Moro (UNIBA), on behalf of Italian Network for Education on Digital Cultural Heritage, Arts and Humanities (DiCultHer), and by Istituto Centrale per il Catalogo Unico (ICCU) of MiBACT. The following partners constitute the Consortium:

- Dipartimento di Studi Umanistici DISUM - Università degli Studi di Bari “Aldo Moro” (Coordinator) - Italy

- Istituto Centrale per il Catalogo Unico delle Biblioteche Italiane - ICCU - Italy

- European Grants International Academy - EGINA Ltd. - Italy

- Center for vocational training to University of Library studies and Information Technologies - Bulgaria

- Global Libraries - Bulgaria Foundation - Bulgaria

- SIA DMG - Latvia

- Kultūras Informācijas Sistēmu Centre - Latvia

- Hellenic Open University - Greece

- All Digital - Belgium

- Public Libraries 2030 - Belgium

3. http://www.ecvet-toolkit.eu/introduction/eqf-ecvet-andother-european-instruments

4. https://ec.europa.eu/esco/portal/home? resetLanguage $=$ true\&newLanguage $=e n$

5. http://www.ecompetences.eu/it/

6. https://ec.europa.eu/jrc/en/publication/digcomp-frameworkdeveloping-and-understanding-digital-competence-europe

7. https:/ec.europa.eu/eurostat/ramon/nomenclatures/index. cfm?TargetUrl=LST_NOM_DTL_LINEAR\&StrNom $=$ CL_ NACE2\&StrLanguageCode $=$ EN\&IntCurrentPage $=30$

\section{ORCID}

Nicola Barbuti (D) http://orcid.org/0000-0003-0817-4235

\section{References}

Beagrie, N. (2008). Digital curation for science, digital libraries, and individuals. The International Journal of Digital Curation, 1(1), 3-16.
Colombati, C., \& Giusti, E. (2016). Il percorso professionale e la carriera del bibliotecario digitale. Biblioteche Oggi, 34, 32-38.

Del Rosso, J., \& Lampert, C. (2013). So you want to be a digital librarian - What does that mean? [Electronic version]. In J. D. Monson (Ed.), Jump-start your career as a digital librarian: A LITA guide (pp. 3-19). Chicago, IL: American Library Association.

Lau, J., Tammaro, A. M., \& Bothma, T. (2012). Libraries driving access to knowledge (A2K). Berlin/Munich: De Gruyter Saur.

Pomerantz, J., Oh, S., Wildemuth, B. M., Hank, C., Tibbo, H. R., Fox, E. A., \& Yang, S. (2009). Comparing curricula for digital library and digital curation education. Proceedings of DigCCurr2009 International Symposium on Digital Curation, Chapel Hill, NC, USA.

Sreenivasulu, V. (2000). The role of a digital librarian in the management of digital information systems (DIS). The Electronic Library, 18(1), 12-20. doi:10.1108/ 02640470010320380

Tammaro, A. M. (2016). Le competenze del bibliotecario digitale. Biblioteche Oggi, 34, 22-31.

Tammaro, A. M., Casarosa, V., \& Madrid, M. (2013). Digital curators' education: Professional identity vs. convergence of LAM (libraries, archives, museums). In M. Agosti, F. Esposito, S. Ferilli, \& N. Ferro (Eds.), Digital libraries and archives: 8th Italian Research Conference, IRCDL 2012, Bari, Italy, February 9-10, 2012, Communication in Computer and Information Science (Vol. 354, pp. 184-194). Heidelberg: Springer.

Tammaro, A. M., \& Myburg, S. (2012). Education for digital librarians: Some European observations. In A. Spink \& J. Heinström (Eds.), Library and information science trends and research: Europe (Vol. 6, pp. 217-245).

Tammaro, A. M., \& Myburg, S. (2013). Exploring education for digital librarian. Meaning, mode and models. Chandos Information Professional Series (pp. 1-26). Chandos Publishing, Oxford. Retrieved September 3, 2019 from https://www.sciencedirect.com/science/article/ pii/B9781843346593500013

Tammaro, A. M., Verheul, I., \& Witt, S. (2011). Digital library futures: User perspectives and institutional strategies (Vol. 146). Berlin/Munich: De Gruyter Saur.

Walek, A. (2018). Is data management a new "digitisation"? A change of the role of librarians in the context of changing academic libraries' tasks. Retrieved September 3, 2019 from http://library.ifla.org/2247/1/139-walek-en.pdf 